\title{
The effect of thermohydrolysis on biological properties of selected chemical compounds
}

\author{
Monika Janas ${ }^{1, *}$, Alicja Zawadzka ${ }^{1}$ \\ ${ }^{1}$ Lodz University of Technology, Faculty of Process and Environmental Engineering, \\ Wolczanska 213, 90-924 Lodz, Poland
}

\begin{abstract}
One of the negative effects of the continuous development of civilization which is observed in recent decades is an increase in the number and variety of pollutants released into the environment. These substances have ecotoxic properties and pose a serious threat to humans and proper functioning of the ecosystem. Their presence in the environment forces the development of new pollution control techniques. One of the latest and very promising methods to destroy organic contaminants using the properties of water which exceeded the critical point is thermohydrolysis in supercritical water. The aim of this study was to investigate thermohydrolysis in supercritical water conditions and to check its suitability for removal of hardly biodegradable organic compounds present in wastewater. Tests for toxicity of these compounds to aquatic organisms such as sewage bacteria, crustaceans and guppy fish were also performed and the degree of their biological decomposition was determined. Biological studies were carried out on starting compounds and after the processes of thermohydrolysis. The research material included p-nitrotoluene sulfonic acid (PNTS), 4,4'-dinitrostilbene-2,2'-disulfonic acid (DNSDS) and 4,4'-diaminostilbene-2,2'-disulfonic acid (DASDS). The research leads to the conclusion that the reactions occurring during hightemperature thermohydrolysis of the three tested compounds are extremely complex. Results of biological studies indicate a significant decrease in toxicity and increase in the biodegradability of products obtained after the process of thermohydrolysis.
\end{abstract}

\section{Introduction}

Uncontrolled economic development proceeding for decades, in particular the intensification of industrial processes, contributed significantly to the pollution of natural environment. One of the industries that has had the greatest impact on the environment is chemical industry. This is due to the synthesis of thousands of new chemical compounds, often very toxic to the environment. Appearance of these substances in the environment forces the development of new techniques of their disposal [1-3].

In the last decade of $20^{\text {th }}$ century considerable attention was paid to research and implementation of the methods which use supercritical fluids as a medium to conduct

*Corresponding author: monika.janas@dokt.p.lodz.pl 
chemical processes. A particularly promising method of destroying organic pollutants is the process of thermohydrolysis in supercritical water which comprises thermal decomposition or transformation of the starting compounds. High effectiveness of this method results from the thermodynamic properties of water which change very rapidly, often by several orders, near the critical point (critical temperature $\mathrm{T}_{\mathrm{cr}}=374^{\circ} \mathrm{C}$ and critical pressure $\mathrm{P}_{\mathrm{cr}}=22.1 \mathrm{MPa}$ ) [4-6]. Viscosity and thermal conductivity of water in the near-critical region decrease rapidly to achieve a clear minimum at a pressure of 22.5--60 MPa, above which a further increase in temperature causes only a small increase in the parameters analyzed. Density and dielectric constant of water beyond the critical point decrease, and this in turn determines high solubility of a huge group of non-polar compounds in water, including gases and organic compounds. At the same time the loss of polarity causes that compounds with an ionic structure practically do not dissolve in it any longer [7-11].

Currently, the process of supercritical thermohydrolysis is not fully explained because of radical changes in the properties of water in the near-critical region. Accordingly, the aim of the study is to explore and present biological aspects of thermohydrolysis of organic compounds in supercritical water. These studies will be used to identify intermediate products formed in this process and to determine their potential use for other technologies. Only exact knowledge of the mechanism and kinetics of these reactions will allow us to control and optimize the process of thermohydrolysis in supercritical water.

\section{Material and research methods}

In the present work, experiments were carried out on model wastewater containing different concentrations of p-nitrotoluene sulfonic acid (PNTS), 4,4'-dinitrostilbene-2,2'-disulfonic acid (DNSDS) and 4,4'-diaminostilbene-2,2'-disulfonic acid (DASDS). The DASDS acid is a valuable intermediate used in the synthesis of stilbene dyes (replacing the carcinogenic benzidine dyes) and optical brighteners. It is a base for the production of several dyes including Brilliant Yellow, Chrysophenine G and Hessian Purple, Curcumin S, Mikado Yellow, Diamine Orange GR and others. Optical brighteners are widely used for bleaching cotton, viscose and paper, as well as to increase the whiteness of photo paper. The DASDS acid is obtained by oxidation of the PNTS acid by ambient air in a strongly alkaline medium, and then reducing the resulting nitro compound, i.e. the DNSDS acid, with the use of iron in a strongly acidic medium (Bechamp reduction). The factor that determines the quality of products and wastewater formed in the process is the efficiency of oxidation of the PNTS acid which ranges from 50 to $85 \%$. The efficiency of reduction, which is the second step of the technological process, is approximately $90 \%$. Because the efficiency of the two steps of DASDS production is relatively low, large amounts of raw material and intermediates get into the wastewater. These compounds are virtually non-biodegradable and toxic to aquatic organisms. The presence of these compounds in wastewater is a major problem for sewage treatment plants [12-15].

In the first stage of the study, solutions containing from 0.016 to $2.0 \mathrm{~g} / \mathrm{dm}^{3}$ for all compounds were subjected to thermohydrolysis. Experiments were carried out at temperature ranging from 20 to $600^{\circ} \mathrm{C}$, at a pressure of $25.0 \mathrm{MPa}$ and at different volumetric flow rates of the reaction mixture through the reactor. Figure 1 shows schematically the set-up for testing the process of thermohydrolysis in supercritical conditions. 


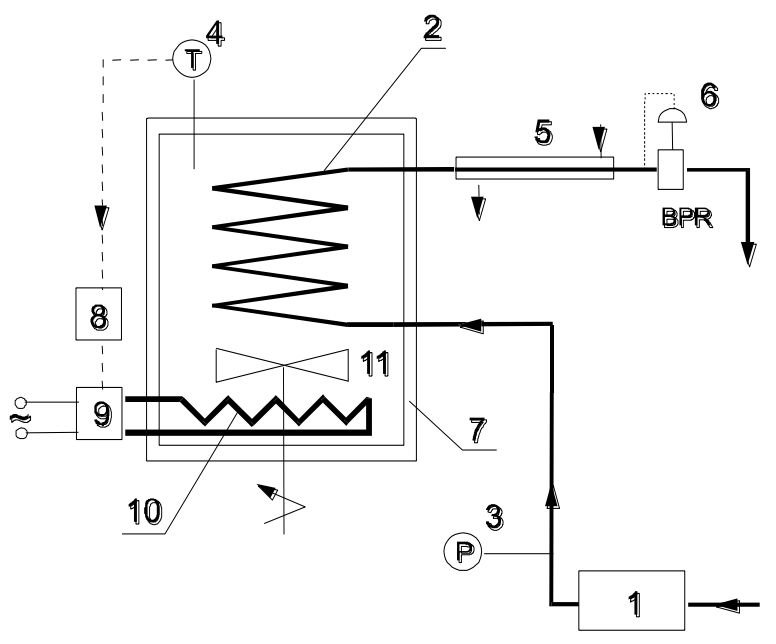

Fig. 1. Schematic of the set-up for testing thermohydrolysis in supercritical conditions.

1 - HPLC piston pump, 2 - flow reactor 3 - pressure measuring system, 4 - thermometer, 5 - cooler, 6 - back pressure regulator, 7 - electric oven, 8 - temperature regulator, 9 - transmitter, 10 - electric heaters.

Analytical methods were used in the study to follow changes in the concentrations of starting compounds and intermediate products during thermohydrolysis in supercritical conditions. Concentrations of the starting compounds and products of thermohydrolysis were determined by high performance liquid chromatography (HPLC). The analysis was performed on a Perkin Elmer liquid chromatograph with a DAD spectrophotometric detector which made it possible to sweep the spectrum from 195 to $360 \mathrm{~nm}$. A standard C18 reverse-phase chromatographic column (Altech) $250 \mathrm{~mm}$ long and $4 \mathrm{~mm}$ in diameter with 5 $\mu \mathrm{m}$ particle diameter was used. Additionally, total organic carbon (TOC) (taken as a sum of all organic compounds, including intermediates, occurring in the reaction mixture) in the samples was determined by a coulometric method using Coulomat $702 \mathrm{Li} / \mathrm{C}$ (Ströhlein).

Biological tests of the compounds subjected to thermohydrolysis were performed in the final stage of the study. Toxicity tests were carried out on aquatic organisms: crustaceans - Daphnia magna Straus (water flea), fish - Lebistes reticulatus Peters (guppy fish), and three species of bacteria that are characteristic of activated sludge: Bacillus subtilis, Proteus vulgaris and Pseudomonas fluorescens.

Biodegradability of the tested compounds was evaluated using the test for determination of the ratio of biological oxygen demand over five days to chemical oxygen demand. The toxicity tests of the reaction mixtures obtained were compared with the toxicity tests of starting materials. The degree of biological decomposition of the reaction mixtures was investigated.

\section{Results}

Figures 2 to 4 show the dependence of reduction degree of the tested acid solutions on the reduction degree of TOC as a function of operating temperature of the reactor for the set 
flow rate of $2.5 \mathrm{~cm}^{3} / \mathrm{min}$. and constant initial concentration of $2 \mathrm{~g} / \mathrm{cm}^{3}$. With such process parameters the highest degree of pollutant reduction was achieved.

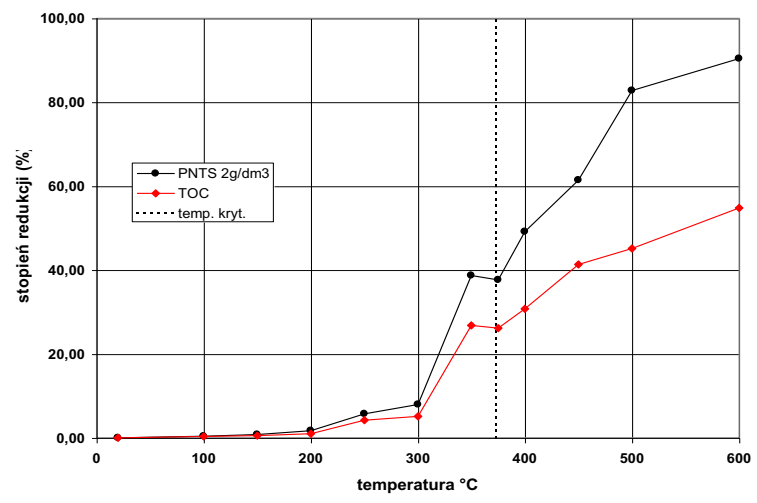

Fig. 2. The dependence of PNTS reduction and degree of TOC reduction on temperature. Volumetric flow rate of fluid through the reactor was $2.5 \mathrm{~cm}^{3} / \mathrm{min}$., inlet concentration was $2 \mathrm{~g} / \mathrm{dm}^{3}$, and pressure $25 \mathrm{MPa}$.

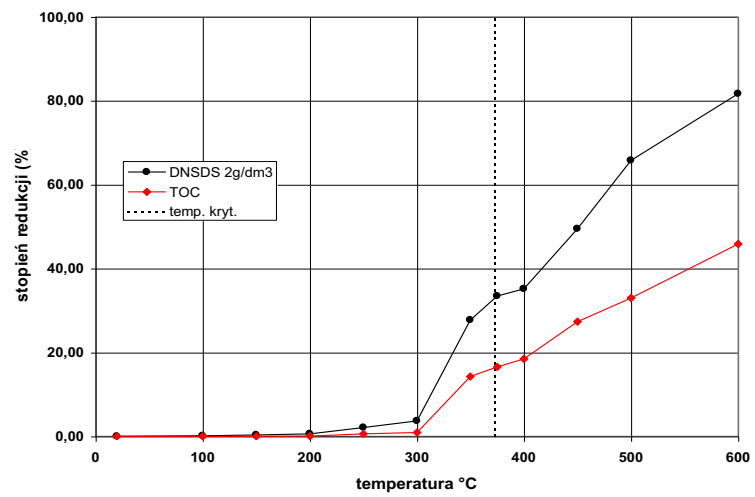

Fig. 3. The dependence of DNSDS reduction and degree of TOC reduction on temperature.

Volumetric flow rate of fluid through the reactor was $2.5 \mathrm{~cm}^{3} / \mathrm{min}$., inlet concentration was $2 \mathrm{~g} / \mathrm{dm}^{3}$, and pressure $25 \mathrm{MPa}$.

The analysis of the curves which characterize the dependence of reduction degree of the compound on temperature leads to a conclusion that conversion occurs only in the nearcritical region. At the initial stage, at relatively low temperatures ranging from 50 to $300^{\circ} \mathrm{C}$, we can observe slight decomposition reaching about $2 \%$. These results are similar for all tested compounds. A lower degree of TOC reduction in relation to the tested compounds can be explained by the fact that in the reaction mass due to the process of thermohydrolysis the compounds were transformed into simpler organic compounds whose structure includes carbon expressed as total organic carbon. 


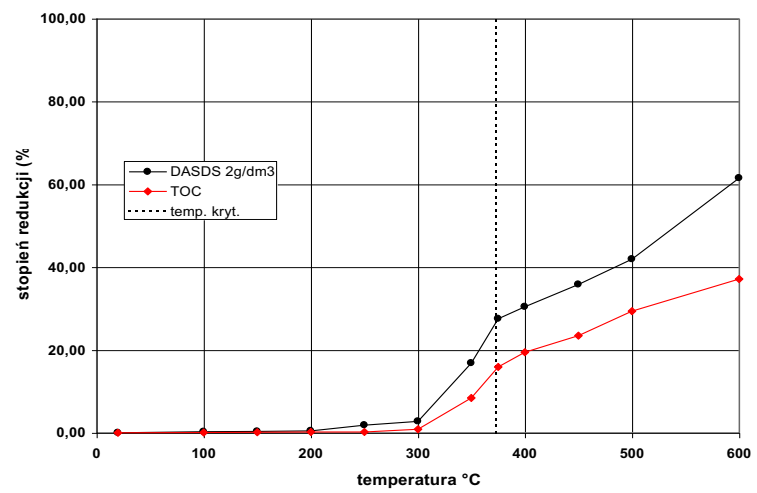

Fig. 4. The dependence of DASDS reduction and degree of TOC reduction on temperature. Volumetric flow rate of fluid through the reactor was $2.5 \mathrm{~cm} 3 / \mathrm{min}$, inlet concentration was $2 \mathrm{~g} / \mathrm{dm}^{3}$, and pressure $25 \mathrm{MPa}$.

Results of biological tests of the reactants subjected to the process of supercritical thermohydrolysis are given in Table 1.

Table 1. The results of PNTS, DNSDS and DASDS toxicity tests.

\begin{tabular}{|l|c|c|c|c|}
\hline Determination & Unit & PNTS & DNSDS & DASDS \\
\hline $\begin{array}{l}\text { Toxicity of LC } \\
\text { Daphnia magna }-96 \text { hours }\end{array}$ & $\mathrm{mg} / \mathrm{dm}^{3}$ & 4.3 & 5.6 & 6.8 \\
\hline $\begin{array}{l}\text { Toxicity of LC } \\
\text { Lebistes reticulatus }-96 \text { hours }\end{array}$ & $\mathrm{mg} / \mathrm{dm}^{3}$ & 68.4 & 154.6 & 178.4 \\
\hline $\begin{array}{l}\text { Toxicity to sewage bacteria } \\
\text { Bacillus subtilis } \\
\text { Proteus vulgaris } \\
\text { Pseudomonas fluorescens }\end{array}$ & $\mathrm{mg} / \mathrm{dm}^{3}$ & 5000 & 5000 & 5000 \\
\hline $\mathrm{mg} / \mathrm{dm}^{3}$ & 5000 & 5000 & 5000 \\
Biological decomposition & $\%$ & 0 & 0 & 0 \\
\hline
\end{tabular}

The $\mathrm{LC}_{50}$ indicators provide information on the compound concentration at which there is a $50 \%$ mortality of the tested species. When examining the toxicity of a compound against sewage bacteria, such concentration of the compound is taken at which no growth of bacteria after $96 \mathrm{~h}$ contact with the tested substance is observed, and a further lower concentration does not have a cidal effect on microorganisms.

There are big problems in carrying out toxicity tests of the biological reaction mixture after thermohydrolysis which can be fully compared with the results obtained for pure compounds. These problems stem from the fact that after the process of thermohydrolysis of the reaction mixture there is not only a single chemical compound but a solution of a mixture of several chemicals. Accordingly, it is impossible to determine the $\mathrm{LC}_{50}$ concentration, i.e. such a concentration at which half of the aquatic organisms survive. In the case of mixtures of chemical compounds we define the degree of dilution at which mortality of organisms is $50 \%$.

Due to the fact that the toxicity of the tested compounds against sewage bacteria is higher than that of compounds used in the process, in a further step of the study no toxicity tests were carried out in relation to these organisms. In the first part of the study preliminary toxicity tests for the products of thermohydrolysis of PNTS, DNSDS and DASDS were performed at temperatures 200,250 and $300^{\circ} \mathrm{C}$, concentration $2 \mathrm{~g} / \mathrm{dm}^{3}$, 
pressure 25.0 MPa and flow rate through the reactor $2.5 \mathrm{~cm}^{3} / \mathrm{min}$ in relation to daphnia. Results of the tests indicated that toxicity of these products of thermohydrolysis did not decrease in relation to this organism.

Therefore, for purposes of this study the toxicity tests were performed for three solutions of the tested compounds at a concentration of $2 \mathrm{~g} / \mathrm{dm}^{3}$ after thermohydrolysis at $400^{\circ} \mathrm{C}$ and $600^{\circ} \mathrm{C}$, pressure $25.0 \mathrm{MPa}$ and flow rate through the reactor $2.5 \mathrm{~cm}^{3} / \mathrm{min}$. Results of these tests are given in Table 2 below.

Table 2. Results of toxicity tests for PNTS, DNSDS and DASDS after thermohydrolysis.

\begin{tabular}{|c|c|c|c|c|c|}
\hline Determination & Unit & Temp. & PNTS & DNSDS & DASDS \\
\hline \multirow{3}{*}{$\begin{array}{l}\text { Toxicity of } \mathrm{LR}_{50} \\
\text { Daphnia magna - } 96 \text { hours }\end{array}$} & \multirow{3}{*}{ dilution } & $20^{\circ} \mathrm{C}$ & $1+465$ & $1+357$ & $1+294$ \\
\hline & & $400^{\circ} \mathrm{C}$ & $1+480$ & $1+367$ & $1+302$ \\
\hline & & $600^{\circ} \mathrm{C}$ & $1+7$ & $1+5$ & $1+4$ \\
\hline \multirow{3}{*}{$\begin{array}{l}\text { Toxicity of } \mathrm{LR}_{50} \\
\text { Lebistes reticulatus }-96 \text { hours }\end{array}$} & \multirow{3}{*}{ dilution } & $20^{\circ} \mathrm{C}$ & $1+29$ & $1+13$ & $1+11$ \\
\hline & & $400^{\circ} \mathrm{C}$ & $1+38$ & $1+17$ & $1+14$ \\
\hline & & $600^{\circ} \mathrm{C}$ & $1+2$ & $1+1$ & $1+1$ \\
\hline \multirow{3}{*}{ Biological decomposition } & \multirow{3}{*}{$\%$} & $20^{\circ} \mathrm{C}$ & 0 & 0 & 0 \\
\hline & & $400^{\circ} \mathrm{C}$ & 0 & 0.6 & 0.8 \\
\hline & & $600^{\circ} \mathrm{C}$ & 95 & 91 & 86 \\
\hline
\end{tabular}

Due to the inability to evaluate toxicity of the solution after thermohydrolysis, given in $\mathrm{mg} / \mathrm{dm}^{3}$, (because of the presence of a mixture of different reactants in different quantities) in relation to fish and daphnia, in this case the degree of dilution $\mathrm{R}_{50}$, i.e. the number of dilutions of the reaction mixture, is determined to obtain a solution in which the organisms mortality reaches $50 \%$.

To compare the two values $-\mathrm{LC}_{50}$ and $\mathrm{LR}_{50}$ for the tested solutions it was calculated that in order to obtain a solution with a concentration of $4.3 \mathrm{mg} / \mathrm{dm}^{3}$ from the initial PNTS solution having a concentration of $2 \mathrm{~g} / \mathrm{dm}^{3}$ it must be diluted approx. 465 times. Then, the resulting solution would have toxicity of $50 \%$. The toxicity of solution after the process of supercritical thermohydrolysis reached $50 \%$ at 8 -fold dilution. Consequently, its toxicity to Daphnia magna at $600^{\circ} \mathrm{C}$ and pressure of $25.0 \mathrm{MPa}$ decreased approx. 60 times. In relation to Lebistes reticulatus an about 15-fold decrease in PNTS toxicity is observed. Accordingly, for DNSDS a 60-fold decrease in toxicity to Daphnia magna, and a 7-fold decrease in the case of Lebistes reticulatus is observed. The toxicity of DASDS after thermohydrolysis to Daphnia magna decreased also about 60 times, and 5 times in relation to Lebistes reticulatus.

Slightly different results were observed for the tested compounds after thermohydrolysis at $400^{\circ} \mathrm{C}$ and pressure $25.0 \mathrm{MPa}$. At this temperature for all tested compounds a slight increase in toxicity to aquatic organisms in comparison with starting substances is observed. This is probably due to the maximum concentration of intermediate products observed at this temperature which are more toxic to aquatic organisms than the tested compounds. Properties of these reactants affect also the fact that we do not observe an increase in biodegradability of the reaction mixture at this temperature.

Results of the biological toxicity studies indicate that due to thermohydrolysis in supercritical conditions at a temperature of $600^{\circ} \mathrm{C}$, pressure $25.0 \mathrm{MPa}$ and flow rate through the reactor $2.5 \mathrm{~cm}^{3} / \mathrm{min}$ of PNTS, DNSDS and DASDS the resulting products have altered properties in relation to aquatic biocenosis as compared to starting compounds. The products of supercritical thermohydrolysis are characterized by low toxicity to aquatic organisms and very high degree of biodegradation. A change in the toxicity of reactants subjected to thermohydrolysis results from a conversion of the tested compounds non- 
degradable by biological oxidation into simple compounds that are highly biodegradable. At the same time the mixture of these compounds exhibits reduced toxicity to fish and crustaceans.

\section{Discussion and conclusions}

In the study experiments were carried out on model wastewater containing different concentrations of p-nitrotoluenesulfonic acid (PNTS), 4,4'-dinitrostilbene-2,2'-disulfonic acid (DNSDS) and 4,4'-diaminostilbene-2,2'-disulfonic acid (DASDS). These compounds are used to produce a large group of dyes and optical brighteners. They are classified as non-degradable organic pollutants which are very difficult to remove from wastewater by conventional methods. This is due to high resistance of these compounds against biological oxidation and their relatively high toxicity to aquatic organisms.

Solutions containing from 0.016 to $2.0 \mathrm{~g} / \mathrm{dm}^{3}$ of all tested compounds were subjected to thermohydrolysis. Studies were carried out in the temperature range from 20 to $600^{\circ} \mathrm{C}$, at a pressure of $25.0 \mathrm{MPa}$ and different volumetric flow rates of the reaction mixture through the reactor.

The studies lead to the conclusion that destructive hydrolysis of the tested compounds is a very slow process. Examining the effect of certain factors on the rate of thermohydrolysis it was found that the process depended on the average residence time of the reaction mixture in the reactor, process temperature and concentration of the starting compound.

Investigation of the PNTS thermohydrolysis results in a conclusion that the maximum reduction of the compound of approx. $100 \%$ is achieved at a flow rate of the reaction mixture equal to $2.5 \mathrm{~cm}^{3} / \mathrm{min}$ and at a temperature of $400{ }^{\circ} \mathrm{C}$ for a starting concentration of $0.016 \mathrm{~g} / \mathrm{dm}^{3}$ PNTS (pressure $25 \mathrm{MPa}$ ). A higher starting concentration of this compound and a different flow rate through the reactor cause that $100 \%$ conversion of this compound is achieved at higher temperatures.

Results of the DNSDS conversion during thermohydrolysis suggest that at a flow rate of the reaction mixture equal to $2.5 \mathrm{~cm}^{3} / \mathrm{min}$ and at a temperature of $600^{\circ} \mathrm{C}$ at a concentration of $0.016 \mathrm{~g} / \mathrm{dm}^{3}$ DNSDS (pressure $25 \mathrm{MPa}$ ) maximum $100 \%$ conversion of the compound is reached. Similarly to PNTS, higher starting concentrations of this compound and different flow rates through the reactor cause that $100 \%$ conversion of this compound is achieved at higher temperatures.

During thermohydrolysis of the tested compounds some amounts of intermediates are formed. This is confirmed by the value of TOC whose degree of conversion is lower than in the tested compounds. This is a result of the presence of other organic compounds in the reaction mixture. The structure of these compounds contains carbon determined as TOC.

The biological toxicity tests indicate that as a result of thermohydrolysis in supercritical conditions at a temperature of $600^{\circ} \mathrm{C}$, pressure $25.0 \mathrm{MPa}$ and flow rate through the reactor $2.5 \mathrm{~cm}^{3} / \mathrm{min}$ of PNTS, DNSDS and DASDS we obtain products with changed properties in relation to aquatic biocenosis as compared to starting compounds. The products of supercritical thermohydrolysis are characterized by low toxicity to aquatic organisms and a very high degree of biodegradation. The change in toxicity of the reactants subjected to thermohydrolysis is a result of conversion of the tested compounds non-degradable by biological oxidation into simple compounds that are highly biodegradable. The mixture of these compounds exhibits reduced toxicity to fish and crustaceans.

\section{References}

1. F. Luck, Catal. Today 53, 81-91 (1999) Wet air oxidation: past, present and future 
2. L. Qian, S. Wang, D. Xu, Y. Guo, X. Tang, L. Wang, Water Res 89 (2016)

3. A. Zawadzka, G. Rogacki, Inżynieria i Aparatura Chemiczna 6 (2004)

4. P.E. Savage, Chem. Rev. 99 (1999)

5. H. Weingartner, E.U. Franck, Angew. Chem. Int. Ed. Engl. 44 (2005)

6. G. Brunner, J. Supercrit. Fluids 47 (2009)

7. H. Pińkowska, P. Wolak, A. Złocińska, Biomass Bioenergy 35, 9 (2011)

8. Z. Shen, D. Yang, S. Wang, W. Wang, Y. Li, Int. J. Heat Fluid Flow 108 (2017)

9. B. Al-Duri, F. Alsoqyiani, I. Kings, J. Supercrit. Fluids 116 (2016)

10. K.M. Benjamin, P.E. Savage, Ind. Eng. Chem. Res. 44 (2005)

11. J. Chen, Y. Wang, S. Ding, J. Ding, M. Li, C. Zhang, M. Zou, JECE 4, 3 (2016)

12. J. Abelleira, J. Sanchez-Oneto, J. R. Portela, E.J. Martinez de la Ossa, Fuel 111 (2013)

13. J.M. Prado, D. Lachos-Perez, T. Forster-Carneiro, M.A. Rostagno, Food Bioprod. Process. 98 (2016)

14. G. Brunner, J. Supercrit. Fluids 96 (2015)

15. A. Kruse, N. Dahmen, J. Supercrit. Fluids 96 (2015) 